\title{
Modified 'Stable Schools' as a Consulting Tool for Organic Dairy Herds
}

\author{
Verena K. Hansmann ${ }^{1}$ Otto Volling ${ }^{2}$ and Volker Krömker ${ }^{3, *}$ \\ ${ }^{1}$ Department of Bioprocess Engineering, Microbiology, University of Applied Sciences and Arts Hannover, Hannover, \\ Germany \\ 2 Ökoring e. V., Visselhövede, Germany \\ ${ }^{3}$ Faculty of Health and Medical Sciences, Section Production, Nutrition and Health, University of Copenhagen, \\ Frederiksberg, Denmark \\ * Corresponding author: E-Mail: Volker.Kroemker@sund.ku.dk; Tel.: +45 35322291.
}

Submitted: 24 September 2019 | In revised form: 23 February 2020 | Accepted: 16 March 2020 |

Published: 12 May 2020

\begin{abstract}
The aim of this study was to examine the opinions of farmers on a consulting project, which was established for organic dairy farms in Northern Germany involving different animal health experts who participated in the meetings. Furthermore, the properties of measures that are of decisive importance for implementation on the farms were identified to improve consultancy services for dairy farming. Once a year, the farmers met on a host-farm in one of three groups consisting of five to nine farms, a facilitator and an expert. At each meeting, a host-farm was visited and the analysed data of all participating farms of the previous year were presented to the group members. Each farmer had the possibility to report on success stories and issues concerning his herd. During discussions, the farmers first proposed mutual farm-specific measures for improving herd health and animal welfare. Afterwards, the expert named possible interventions and commented on the given measures of the farmers. All measures were noted by the facilitator. At the end of each meeting, each farmer could choose which of the given measures he wanted to implement. Open group-interviews as well as anonymous questionnaires for the farmers were used at the meetings in winter 2016/2017 to evaluate their perception of this consulting project and to determine which properties of measures were important for implementation on the farms. Based on the results of this study, the participating farmers were very positive towards this kind of consulting project. They favoured the participation of an expert during the meetings and the analysis of farm-specific data. Farmers mostly chose measures for implementation proposed by farmers and approved by the expert, followed by those proposed by the expert only. Measures were chosen when they were practical in the implementation, effective, efficient and took a low additional workload for implementation.
\end{abstract}

Keywords: consulting; dairy farming; experts; fellow farmers; herd health; improvement; learning-groups; organic farming; welfare 


\section{Introduction}

Achieving and maintaining good animal health and welfare is an important aim in organic livestock husbandry (Council Regulation (EC) No. 834/2007), requiring continuous development as well as management adjustments on organic farms [1]. In order to attain a high welfare level, management plays an important role [2]. However, managing a farm according to organic principles does not automatically guarantee high levels of animal health and welfare. With regard to the great impact of farm managers' behaviour and attitudes on animal health and welfare [2], implementing animal health plans was recommended in order to motivate organic farmers to continuously and actively improve animal health and welfare on their farms [3]. Herd health plans should be based on the assessment and evaluation of current farm data and real farm circumstances combined with feedback, planning the implementation of farm-specific interventions in a continuous process of development and improvement of animal health and welfare [1,4]. Furthermore, herd health planning should involve external advisers and knowledge, be written down, highlight good aspects and success stories as well as address problem areas on the farms in order to promote the learning process [5].

During recent years, several successful approaches focusing on herd health planning for organic production were established in Europe [1,6-8]. In Denmark, so-called 'Stable Schools' were established. The principle of 'Stable Schools' is the exchange of knowledge between farmers who face similar challenges and work for a common aim. These farmers are able to advise mutually on practical measures [6]. 'Stable Schools' have their origin in 'Farmer Field Schools' (FFS) which were developed for farmers in developing countries. The basic idea of FFS is the exchange of knowledge and experience, interactive education and strengthening the farmers' personalities and, especially, common learning in groups of farmers who meet on hostfarms without the presence of any expert like a veterinarian or adviser [6]. Vaarst et al. [6] suggested that farmers benefit most when there is a link between the discussed issues and the real situation on their farms. If this is the case, farmers develop the necessary knowledge by themselves. In 'Stable Schools', the farmers are equal and learn from each other by giving mutual advice. The only external person who participates in these on-farm meetings is a facilitator who guides the process [6]. He or she does not offer advice but leads the meeting as well as the discussion. Furthermore, the facilitator encourages the host-farmer to be active and the fellow farmers to be critical and to feel free to propose measures to solve farm-specific problems of the host-farm $[6,9]$. Additionally, the facilitator provides and evaluates current farm data to present these to participating farmers in 'Stable Schools' [10]. Within the ANIPLAN-project, 'Stable Schools' were adopted in seven European countries, including Austria, Denmark, Germany, Norway, Switzerland, the Netherlands and the United Kingdom [7]. Different 'Stable Schools' or herd health plan projects handled different animal health and welfare issues such as improving udder health, phasing out antibiotics on organic dairy farms through herd health plans $[3,7,11,12]$, or lameness reduction in dairy herds $[3,13]$. Especially in dairy production, 'Stable Schools' have proved to be useful to enhance animal health and welfare in recent years [3,6,8,11,13,14].

The attitudes of farmers participating in 'Stable Schools' or other herd health plan projects were mainly very positive $[4,6,15]$ and the compliance of dairy farmers to implement measures was high $[3,15]$. Reasons given for high implementation of interventions included ease of implementation, integrability in the farm routine and daily working routine, and the requirement of only little capital [3]. Good acceptance of 'Stable Schools' and herd health plans in general depends on the involvement of the farmers in the process $[6,7,9,11,13]$ as well as the farm-specific goals and measures [6,9]. Furthermore, an important point for the success of herd health plans is the use and evaluation of current farm data $[15,16]$. Moreover, the interaction between farmers and external consultant was mentioned to be a major reason for the effectiveness of herd health plans [1]. External advice in general was identified as an important precondition for a successful herd health planning $[1,12]$. This is due to the fact that participation of external persons offers a more objective view and inspiration and may help to identify issues and to find solutions $[1,6,15]$. Therefore, not only farmers but also agricultural advisers or veterinarians took part in consulting projects. Indeed, a veterinarian who is interested in organic farming as well as in herd health is a potential partner for farmers [6]. Thus, the 'erfa' (abbreviation for 'erfaring' which means experience in Danish) or 'Farmer Experience Exchange Groups' were established in Denmark, consisting of farmers who often manage similar farms and a professional expert like, for example, a veterinarian who meet up on host-farms. Sometimes even a specialist expert is invited to take part in such meetings. This kind of project combines the common learning effect with a professional expert but focuses on a special topic than on the farm-specific issues [6,9]. However, according to Bourdieu [17], such combinations in general run the risk of an imbalance within the group as the professional probably dominates the non-professionals, in this case the farmers. Possible reasons are: the professional's authority, on the one hand, and the common expectations regarding his or her knowledge and abilities, which may be perceived to be superior to those of the 'non-professionals', i.e. farmers, on the other hand. Nevertheless, it should not be forgotten that the professional, like for example the veterinarian, probably has important knowledge that the farmers might lack and, hence, can benefit from [6].

The aim of the present study was to investigate the famers' opinions on a consulting project for organic dairy herds in Northern Germany to improve consultancy services to organic dairy farming. Specifically, we (1) asked about the role of the expert taking part in the meetings; and (2) aimed to identify properties of those suggested measures that are chosen for implementation on the par- 
ticipating farms in order to make herd health planning more successful in future.

\section{Material and Methods}

\subsection{The Consulting Project and the Farms}

In July 2011, the University of Applied Sciences and Arts Hannover, Hannover, Germany started a consulting project for farmers of organic dairy farms in Northern Germany in cooperation with the Competence Centre for Organic Farming called "Ökoring e. V." based in Visselhövede, Lower Saxony, Germany. The aim of this project was to improve the animal health and welfare of organic dairy herds. At the outset, managers of organic dairy farms, who were familiar with the Competence Centre for Organic Farming due to prior consultation meetings, were invited via questionnaire to participate voluntarily in the fee-based consulting project. After issuing the invitations, 17 farmers agreed to take part in this project. Three farmers quitted the project after the consulting meetings in winter 2012 without giving a reason but between 2013 and 2016, nine other organic dairy farm managers joined. Thus, for this analysis, 17 organic dairy farms were consulted in 2011 and 2012, respectively. As two of the 17 farmers participating in the project in winter 2012 could not attend the meetings in winter 2012, only 15 farmers took part. In December 2016 and January 2017, the farmers of 23 organic dairy herds participated in the consulting meetings.

All participating farms were located in Northern Germany, predominantly in Lower-Saxony but also in SchleswigHolstein and Bremen. All participating herds had completed the transformation process from conventional to organic dairy farming by 2011 . The herd size was $12-290$ cows. All farms ensured their dairy herds access to pasture, at least during the summer months. The participating farmers mainly kept dairy cows of the Holstein Friesian breed but also included other breeds like German black pied cattle, crossbreeds of dairy and beef cattle, Angeln cattle, the Simmental breed and Rotvieh.

At the beginning of the consulting project, the farmers were allocated to one of three groups depending on the annual milk yield per cow, their location and similar economy. In this way, three groups with nearly the same number of participants were formed. Group one included between five (2012) and seven (2016/2017) farms, group two consisted of between five (2012) and nine (2016/2017) farms and farmers from seven farms participated in the meetings of the third group in 2012 and 2016/2017, respectively. Usually, the same farmers always met, although the groups were replenished after individual farms had left.

\subsection{The Meetings}

In the first eighteen months, each group met three times. Then each group met once a year, mostly in the winter months.
During the consulting years, farm data were gathered from every herd based on the monthly dairy herd improvement test with information on milk yields, fat and protein components, somatic cell counts, cow lifetime, number of lactating cows, lactation number, new infection rates during lactation and dry-period, fertility data etc. on the one hand and on farm-questionnaires on the other hand. In the questionnaires, the farmers documented the frequency of calving, clinical mastitis, lameness, fertility disorders, metabolic diseases and calf diseases as well as the treatments of these diseases.

Ahead of the annual meetings, the farmers were asked over the phone to name animal health issues which had occurred since their last meeting. Depending on the predominant animal health problems of the participating farms per group, which emerged during the phone conversations with the farmers but also derived from the analysed data of the monthly dairy herd improvement test as well as from questionnaires, an expert, like a veterinarian, with specific know-how on for example udder health, claw health, metabolic diseases or fertility was invited to join those meetings. All experts had over ten years' experience in immediate production-related, agricultural consulting.

The procedure of those regular meetings was mostly identical: first, the members of one group as well as the staff member of the Competence Centre for organic farming (called facilitator) and an expert met on a farm of one participating manager of the group (host farm). The same facilitator was involved in all three groups. Each meeting took place on another farm in turn until all farms in one group had been visited by the group members.

At the beginning of each group meeting, the annual mean of the collected data of all herds in the mutual comparison was presented to all farmers in overview tables so that the farmers could benchmark their herd and animal health data against those of other herds with similar milk yields. Afterwards, the analysed monthly data of the dairy herd improvement tests and of the questionnaires of the last twelve months of all participating herds were shown to all group-members one after another. Due to the comparisons of the annual means of analysed data of the present year with the data of the past years for each herd, it could be checked whether or not the presumptions of the farmers regarding animal health problems during the last twelve months were reasonable. Such presumptions, collected during phone calls, were, for example, high somatic bulk milk cell counts, a high rate of new intramammary infections during the dry-period, stillbirths or lameness.

After presenting the data of one farm, the farmer was given the opportunity to report a success story of his farm by telling the group which aspect of herd health had improved and the possible reasons for this. Then the farmers jointly discussed the current animal health problems on that particular farm and put forward recommendations to improve these issues. In addition, the farmers were encouraged to ask each other questions and the experts attending the event. The facilitator led the discussions. Afterwards, 
the expert was given the opportunity to comment on the data, the farm-specific animal health problems and gave advice to solve these issues. The suggested measures were assorted to one of three groups depending on their source to assess the impact of different sources on the farmers' choices which measures to implement on their farms. Those measures given by farmers as well as those of the expert and those suggested by the farmers first and then confirmed by the expert, were noted for each farm by the facilitator.

Afterwards, the farmers could decide for themselves which and whose suggestions they wanted to put into practice, naming reasons for this so that management plans were compiled. Again, the chosen measures were noted down by the facilitator. The farmers took home a copy of the chosen farm-specific measures written down by the facilitator during the meeting so that they could see in detail which measures they had chosen for implementation. This procedure was repeated for every farm. After presenting the data, the farm-specific presentation with analysed herd data was sent to each farmer by e-mail.

At the end of the meetings, the participants inspected the host farm on a comprehensive guided tour led by the host farmer. If necessary, the given farming conditions could be better assessed by all farmers and the experts and further improvement measures could be discussed.

The consulting meetings in 2012 and 2016/2017 were chosen for data evaluation because farmers who had started the project in 2011 were familiar with their group members in winter 2012 on the one hand and had got to know the procedure of the meetings until then on the other hand. Moreover, there was enough time - also for fellow farmers who joined the project later- to get familiar with the group members and to deepen their knowledge of special health topics during this period (between 2012 and 2016/2017). The evaluation years 2012 and 2016/2017 were especially important as udder health issues were discussed intensively in the annual consulting meetings so that there might have been a knowledge gain and learning effect of the farmers.

During the meetings in December 2016 and January 2017, an anonymous questionnaire was distributed to each participating farmer. Farmers were prompted to answer the following five multiple-choice questions: "How important is the experience/knowledge exchange with fellow farmers/an expert?" (question no. 1), "Did you feel intimidated or were you reluctant when an expert took part at the annual meeting?" (question no. 2), "Do you stay in contact with the fellow farmers of your consulting group apart from the annual meeting and if yes, how often?" (question no. 3), "How important is the farm visit of the group fellow farmers for you?"(question no. 4) and "Do you find the visit of the fellow farmers' farms educational or useful?" (question no. 5). Moreover, the farmers had to assess the importance of properties for the measures to be chosen for implementation on their farms (no. 6). Therefore, they had to rank at least six predetermined properties ('additional daily workload for implementation', 'additional workload until the measure can be implemented (e.g. planning, reconstruction, installation)', 'duration from the implementation of the measure to the detection of effectiveness', 'effectiveness and efficacy (business-related)' as well as 'extent of structural and technical changes on the farm' and 'workable and practical implementation in everyday life') and optionally name and rank more factors in descending order of importance (from $1=$ most important to 6 = least important). After analysing all anonymous questionnaires, the property with the lowest total was stated to be the factor most important for choosing the measure to be implemented on a farm.

\subsection{Statistical Analyses}

Data were collected and analysed using the programs Excel (Microsoft Corporation) and SPSS (IBM SPSS 24.0, Chicago USA). By using the Chi-square-test, the distribution of the data was compared. Significance was assumed at $p<0.05$.

\section{Results}

The majority of the participating farmers found the exchange of experience and knowledge with both fellow farmers and experts "very important" (Table 1). None of the farmers felt intimidated when an expert took part at the annual meeting (Table 1). Furthermore, the majority of farmers had contact with group fellow farmers between 1 to 2 times a year (Table 1). Most farmers found the farm-visits of group fellow farmers "important" and "absolutely" educational or useful (Table 1). The evaluation of no. 6 of the questionnaire indicated that a workable and practical implementation in everyday life, effectiveness and efficacy of measures as well as the additional daily workload for implementation were the most important properties of measures for implementation (Table 2). The properties of measures are listed in descending order of priority in Table 2, from properties of measures with the most importance (no.1) to properties of measures with the least importance to get chosen by farmers for implementation. In addition to Table 2, two farmers gave explicit definitions for the option "others". The farmers mentioned easy physical performing of the measure and successful implementation thereof as being the second most important criterion. 
Table 1. Evaluation of the results of the anonymous questionnaires $(n=25)$, questions $1-5$.

\begin{tabular}{|c|c|c|c|c|}
\hline \multicolumn{5}{|c|}{ 1) How important is the experience/knowledge exchange with... } \\
\hline & Very important & Important & Less important & unimportant \\
\hline a) ...fellow farmers? & 22 & 3 & 0 & 0 \\
\hline b) ...experts? & 23 & 2 & 0 & 0 \\
\hline \multicolumn{5}{|c|}{ 2) Did you feel intimidated or were you reluctant when an expert took part at the annual meeting? } \\
\hline 25 & & 0 & & 0 \\
\hline no,absolutely not & & yes, a little bit & & yes, very much \\
\hline \multicolumn{5}{|c|}{ 3) Do you stay in contact with the fellow farmers of your consulting-group apart from the annual meeting and if yes, how often? } \\
\hline 2 & 9 & 13 & 1 & \\
\hline yes, many times & yes, sometimes & yes, rarely & no, never & \\
\hline ( $>5$ times/year) & (3 to 5 times/year) & (1 to 2 times/year) & & \\
\hline \multicolumn{5}{|c|}{ 4) How important is the farm-visit of group fellow farmers for you? } \\
\hline 9 & 16 & 0 & 0 & \\
\hline very important & important & less important & unimportant & \\
\hline \multicolumn{5}{|c|}{ 5) Do you find the visit of the felow farmers' farms educational or useful? } \\
\hline 22 & & 3 & & 0 \\
\hline yes, absolutely & & yes, but moderately & & no, absolutely \\
\hline
\end{tabular}

Table 2. Ranking of properties of measures to get chosen for implementation on organic dairy farms.

\begin{tabular}{lll}
\hline Rank $^{*}$ & Property of measure & Total points \# \\
\hline 1 & Workable and practical implementation in everyday life & 70 \\
$2 \mathrm{a}$ & Effectiveness and efficacy (business-related) & 75 \\
$2 \mathrm{~b}$ & Additional daily workload for implementation & 75 \\
3 & Extent of structural or technical changes on the farm & 104 \\
4 & Additional workload until the measure can be implemented (e.g. planning, reconstruction, installation) & 106 \\
5 & Duration from the implementation of the measure to the detection of effectiveness & 123 \\
\hline * Descending according to importance: from number 1 being the most important criterion to number 5 being the least important criterion for \\
choosing a measure for implementation on a farm. \# Sum of points given by participating farmers on the anonymous questionnaire at the \\
consulting meetings in winter 2016/2017.
\end{tabular}

During the meetings in 2012, a total of 127 measures to improve herd health were suggested, whereas 227 measures (some examples of proposed measures concerning certain problems of udder-health are listed in Table 3) were suggested during the meetings in 2016/2017. Identical measures suggested by the same source (e.g. fellow farmers) for the same issue in the same group were not counted repeatedly. While the expert suggested most of the measures proposed in 2012, the amount of measures proposed by the farmers first and then approved by the expert represented the highest percentage in the meetings in winter 2016/2017 (Table 4, column a). The number of measures proposed by the fellow farmers only, the expert only as well as the number of measures proposed by the farmers first and then approved by the expert differed significantly between 2012 and 2016/2017 ( $<<0.001$; Table 4, column a).

The number of chosen measures for implementation proposed by the farmers only, as well as proposed solely by the expert differed significantly not only in $2012(p<0.001)$ but also in 2016/2017 ( $p<0.001$; Table 4, column b). Measures proposed by fellow farmers only were rejected by the farmers in most cases, while the proportion of chosen measures was much higher among the measures proposed by experts only, or by both experts and farmers (Table 4, column b). Furthermore, the number of chosen measures proposed solely by the farmers and only by the expert as well as the number of chosen measures proposed by the fellow farmers first and later approved by the expert differed 
significantly between 2012 and 2016/2017 ( $p<0.001$; Table 4 , column b).

The amount of chosen measures proposed by fellow farmers only in relation to the total chosen measures was the lowest in 2012 as well as in 2016/2017 (Table 4, column c). The highest percentage of chosen measures in relation to total chosen measures was represented by the measures proposed by the expert exclusively in 2012 and by the measures suggested by the fellow farmers first and then approved by the expert in 2016/2017 (Table 4, column c).

Within the context of the open feedback rounds at the end of each group meeting, farmers mentioned that they really liked the very informative exchange of knowledge and experience with open-minded fellow famers and the expert. Openly discussing as a group proposed measures to solve their individual farm-related problems and those of the other farmers was very important, educational and highly motivating and offered an opportunity for exchanging information about topics which not every group member was familiar with. Furthermore, they appreciated the participation of an expert in each meeting. Receiving the expert's approval of their proposed measures made them feel more confident. The critical mindset of the group members, including the experts, put "positive pressure" on the farmers, as they commented. They were also grateful for the detailed data evaluated during the year and for the annual summary report. They especially highlighted the data selection, the detailed presentation and the kind of approach to and the distribution of the data which they began to understand more and more. Especially the presentation of the development over several years and over the previous twelve months was important to detect tendencies of herd health parameters. Effects of measures which had been implemented during the previous year were presented simply and clearly for the farmers to follow. In addition, the participating farmers welcomed the direct reciprocal comparison of all herds of the group members at the beginning of each meeting. The mutual comparison was motivating for the farmers to improve herd health and animal welfare and to achieve their individual aims. To name problems of the previous year regarding herd health prior to the annual meetings was effective as farmers had to consider them, go through last year's performance again and give an honest assessment to the facilitator. Moreover, they welcomed that the farmers themselves should specify which suggested measures he or she wanted to implement on their farm and to name reasons for that. Taking these decisions home in a written form served the purpose of a reminder which also helped the farmers to remain motivated in their daily work.

Two groups determined that the maximum group size had been reached so that no more farmers should be added to the existing groups, but that (a) new group/s should be formed.

Table 3. Examples of proposed measures concerning the improvement of certain udder-health problems in organic dairy herds.

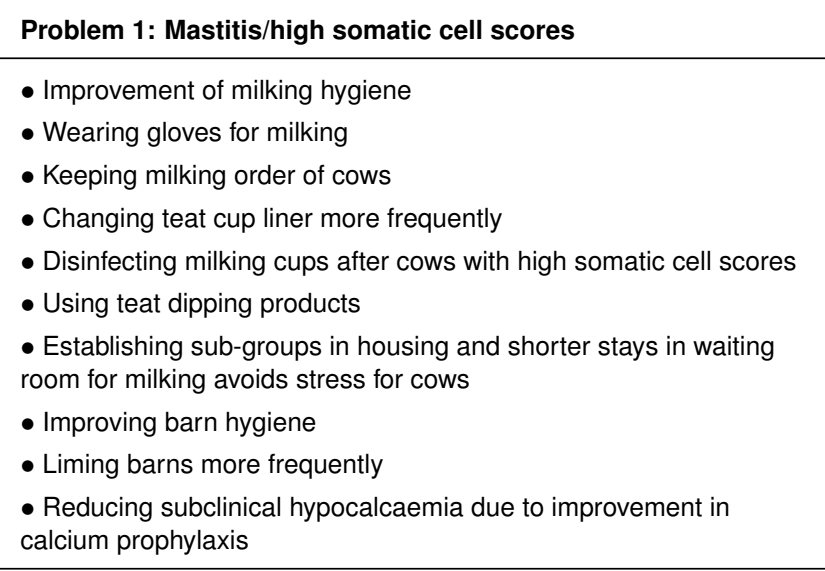

Problem 2: High rate of new intramammary infections during dry-period

- Increasing the amount of bedding

- Improving the hygiene in calving barns

- Using more teat sealer

- Carrying out a Californian mastitis test for each cow before drying off and a bacteriological examination of milk samples with high somatic cell counts

- Using antimicrobial drying agents for cows with positive bacteriological results of milk samples

- Feeding minerals during drying-off

- Administering a selen-bolus at drying-off

- Carrying out a ketosis-test one week ante partum 
Table 4. Analysis of the consulting meetings in 2012 and in 2016/2017.

\begin{tabular}{|c|c|c|c|}
\hline \multicolumn{4}{|c|}{ Consulting meeting 2012 (15 farmers of 15 farms took part) } \\
\hline & a) & b) & c) \\
\hline & $\begin{array}{l}\text { total no. of proposed measures } \\
(n=127=100 \%)\end{array}$ & $\begin{array}{l}\text { measures chosen for } \\
\text { implementation from the total of } \\
\text { a) }(n=53=41.7 \% \text { of a) })\end{array}$ & $\begin{array}{l}\text { total no. of measures chosen for } \\
\text { implementation }(n=53=100 \%)\end{array}$ \\
\hline Source of proposed measures & $\begin{array}{l}\text { Proposed measures listed by } \\
\text { source }\end{array}$ & $\begin{array}{l}\text { Chosen measures in relation to } \\
\text { source of a) }\end{array}$ & $\begin{array}{l}\text { Measures chosen for } \\
\text { implementation listed by source }\end{array}$ \\
\hline Fellow farmers & $22.8 \%(n=29)^{3}$ & $10.3 \%(n=3)^{1.4}$ & $5.7 \%(n=3)$ \\
\hline Expert & $56.7 \%(\mathrm{n}=72)^{3}$ & $51.4 \%(n=37)^{1.4}$ & $69.8 \%(n=37)$ \\
\hline Fellow farmers and expert & $20.5 \%(n=26)^{3}$ & $50.0 \%(n=13)^{4}$ & $24.5 \%(n=13)$ \\
\hline \multicolumn{4}{|c|}{ Consulting meeting $2016 / 2017$ ( 25 farmers from 23 farms took part) } \\
\hline & $\begin{array}{l}\text { Total no. of proposed measures } \\
(\mathrm{n}=227=100 \%)\end{array}$ & $\begin{array}{l}\text { measures chosen for } \\
\text { implementation from the total of } \\
\text { a) }(n=72=31.7 \% \text { of a) })\end{array}$ & $\begin{array}{l}\text { total no. of measures chosen for } \\
\text { implementation }(n=72=100 \%)\end{array}$ \\
\hline Source of proposed measures & $\begin{array}{l}\text { Proposed measures listed by } \\
\text { source }\end{array}$ & $\begin{array}{l}\text { Chosen measures in relation to } \\
\text { source of a) }\end{array}$ & $\begin{array}{l}\text { Measures chosen for } \\
\text { implementation listed by source }\end{array}$ \\
\hline Fellow farmers & $31.3 \%(\mathrm{n}=71)^{3}$ & $11.3 \%(n=8)^{2.4}$ & $11.1 \%(n=8)$ \\
\hline Expert & $27.3 \%(\mathrm{n}=62)^{3}$ & $45.2 \%(n=28)^{2.4}$ & $38.9 \%(n=28)$ \\
\hline Fellow farmers and expert & $41.4 \%(n=94)^{3}$ & $38.3 \%(n=36)^{4}$ & $50.0 \%(n=36)$ \\
\hline
\end{tabular}

a) Amount of measures proposed only by fellow farmers or the expert or by fellow farmers as well as the expert in relation to the total number of proposed measures, b) the percentage and number of measures chosen for implementation by the farmers in relation to the number of proposed measures for each source in a), c) the amount of measures from different sources chosen by the farmers to implement in relation to the total number of chosen measures.

${ }^{1}$ Significant difference $(p<0.001)$ between the number of chosen measures for implementation proposed exclusively by fellow farmers and proposed solely by the expert in 2012.

${ }^{2}$ Significant difference $(p<0.001)$ between the number of chosen measures for implementation proposed exclusively by fellow farmers and proposed solely by the expert in $2016 / 2017$.

${ }^{3}$ Significant difference $(p<0.001)$ between the number of proposed measures for each source between 2012 and 2016/2017.

${ }^{4}$ Significant difference $(p<0.001)$ between the number of chosen measures proposed by the fellow farmers, the expert and proposed by the fellow farmers and later approved by the expert between 2012 and 2016/2017 $(p<0.001)$.

\section{Discussion}

\subsection{Learning in Farmer-groups and the Role of External Input}

To improve animal health and welfare, herd health planning has been stated as an important and continuous tool for herd management in recent years [3]. One way of establishing this opportunity to improve herd health and welfare is to form small groups of farmers working together to exchange experience and knowledge and to provide a common learning platform [6].

In learning groups in general, learning happens to be a mutual common social process [1]. For successful development of learning in groups, the following preconditions of the group were defined: mutual trust and respect of the participants, an open-minded attitude and openness to the whole group to receive comments and constructive criticism as well as suggestions for potential improvement and a high level of motivation of all group members $[6,10]$. Furthermore, having equal rights to report about experiences, conducting honest dialogues and being able to contribute are important prerequisites of the participants to make the herd health planning in groups successful [6]. These characteristics of the discussion-groups were appreciated by the farmers participating in the present study.

In general, external input was assessed positively and as important by farmers for animal health and welfare planning $[1,6,9,12,15]$, which is in accordance with the opinion of the participating farmers in the present study. The interaction between the farmer and an external person like, for example, a colleague, a veterinarian or an adviser was found to be a fundamental element of successful herd health planning. Therefore, external persons should be involved as advisers in improving animal health or welfare [12]. As external persons often see things differently than someone who works in the same environment every day [6,15], their participation can be beneficial to identify problem areas as well as to provide solutions or inspiration by exchanging observations and sharing reflections on the on-farm situations [12]. Meeting and discussing with external persons was the main motivation to join 'Stable Schools' for some 
farmers $[4,14]$ as 'discussing with the farmers is what gives the most' [4]. New input and discussing farming methods help farmers realise why they work the way they do and provide a great opportunity for them to learn from more experienced farmers [4].

\subsection{Farmer Groups and the Involvement of External Experts}

Different approaches of farmer groups are common in animal production in many countries [4,6]. Visiting farms of fellow farmers was appreciated, just like in the present study because farmers liked the opportunity to have a look around on other farms and to compare the animals there with their own [4]. Additionally, they enjoyed sharing knowledge and ideas from other farms which could be implemented on their own farms [4].

The facilitator taking part in the present study had the same role as in previous surveys of 'Stable Schools' [4,6]. He did, for example, not take part as an expert, but guided the decision-making process and directed the discussion $[4,6,9,10]$. Moreover, the facilitator encouraged the farmers to take an active part in the meetings being curious, critical and taking on an advisory role, just like it was in another herd health planning project [6]. Another important task of the facilitator, not only in the present study, was to prepare the agenda of the meetings and to write down the measures chosen for implementation for each farmer [4,6]. This written plan containing clear and concise points of the discussion [9] was most welcomed and was perceived as being very important, not only by the participating farmers of the present study [4]. As a written plan confronts the farmers with the aims and measures they have wanted to implement since the last meeting, it helps them to be active in achieving their aims $[4,9]$.

As the present project included only organic dairy farmers, the advantage of the facilitator being also a staff member of the Competence Centre for Organic Farming was that he could answer upcoming specific questions regarding organic principles and the Council Regulation (EC) No. 834/2007 during the discussion. By integrating not only a facilitator but also an expert into each consulting-group because, according to Vaarst et al. [10], discussions with experts can be of great benefit for all participants of discussion groups, the present project combined characteristics of 'erfa-groups' and 'Stable Schools' but without ensuring complete equality among participants as in 'Stable Schools' $[4,6]$.

The combinations of farmers and experts like veterinarians, may increase the risk of a disparity in a group or lead to a permanent asymmetric power relationship as the experts might dominate the 'non-professionals', in this case the farmers [6,17]. Furthermore, this symbolic imbalance may affect the cooperation between farmers and veterinarians as well as the communication between these participating groups [6]. Vaarst and Roderick [18] suggested that farmers might be less open-minded and share their knowledge and experience less freely when an expert attends the meetings as they think the expert is the person who gives the right answers as well. These fears could not be confirmed in the present study. On the contrary, the farmers participating in the present study mentioned that they appreciated the participation of an expert and felt more confident and reassured after the measures proposed by them had been approved by the expert. They also mentioned that the critical way of thinking of both, the fellow farmers as well as the expert, exerted some kind of positive pressure on these farmers. In any case, a respectful communication of the farmers with each other as well as between farmers and professionals is paramount [1]. However, by integrating a facilitator or an expert, there is, of course, some risk of disrupting the dynamics of a discussion within a group of farmers. To avoid interrupting the group dynamics during the discussion, the facilitator or expert should speak at the very end of it [9].

Moreover, Vaarst et al. [6] considered that, assuming that the farmers trust the expert and that the advice given by the latter is of interest for the farm, farmers might rather follow the expert's advice. This assumption was confirmed by the results of the present study: if the farmers had the choice, they rather chose measures to put into practice proposed by the expert only or by the farmers as well as by the expert than measures proposed only by their fellow farmers. A possible reason for that might be that the farmers had more trust in the measures proposed by the expert regarding correctness, usefulness and effectiveness than in the measures proposed by their fellow farmers. Since the expert also commented on measures proposed by farmers which he considered to be incorrect, unnecessary or useless and gave reasons for this, these meetings had a learning effect for farmers as well. This learning effect was shown by the significantly higher number of proposed measures given by the farmers first and later assessed by the expert in 2016/2017 compared to the number in 2012 in the present study. This fact emphasises the importance of an expert participating in the annual consulting meetings, although a significant learning effect in 'Stable Schools' is also mentioned [6]. Other reasons for this significant difference might be that the farmers in a consulting-group became familiar with each other's way of behaving over time so that they probably could better assess how the other farmers would react after being given advice to improve herd health. Hence, the communication in consulting-groups might have become more open and the farmers were able to understand farm-specific problems of other farms after some time.

\subsection{Current Farm-specific Data}

Herd health plans should be based on the knowledge of the current health and welfare status of a herd based on farm data to promote farm-specific planning $[12,15,16]$. Bell et al. [16], who gathered data using questionnaires, also stated that using and reviewing current farm data was necessary to make herd health planning effective. The farmers 
in the present study emphasised the importance of data selection as well as their detailed presentation as also other farmers had done in the past [15]. Previous surveys [1,9] also described the relevance of presenting data which are understandable and available to the farmer. The advantage of an expert taking part in the consulting meetings is that the farmers learn to understand the meaning and correlations of presented parameters through explanations by the expert.

In addition, the participating farmers referred positively to the presentation of their farm data not only in comparison with the individual farm data of recent years but also in contrast to data of other farms in the group. This kind of benchmarking was motivating, this point also being mentioned by the participating farmers of the present survey during the open feedback rounds [12]. Furthermore, this kind of benchmarking is effective for achieving an aim and can also be encouraging for the discussion and improve the farm-situation $[7,10]$. Moreover, presenting data of the last years and the last twelve months can help the farmers to detect tendencies of herd health parameters even if this development of parameters has not been noticed by them in their herds so far. The early detection of negative developments of certain herd health parameters can help to react specifically by implementing measures. In the present study, the realistic assessment of farm-specific data, especially with regard to the whole on-farm situation, was important to develop the right farm-specific goals.

The challenge to name problem areas of the current year made the participating farmers reflect on what had happened in their herds during that year, which is in accordance with previous surveys $[4,6]$. Moreover, the presentation of the farms' individual and current data in comparison to the data of the years before clarified whether or not the "gut instinct" of the farmers regarding the problem issues of the current year was right. On the other hand, we discovered that telling others a success story concerning one's own herd was motivating for all participants. Therefore, these success stories seem to be important elements when farmers share their experience(s) with their fellow farmers. This is confirmed by other surveys, too $[1,6]$.

\subsection{Compliance Rates and Reasons for and Against Choosing Measures for Implementation}

Another crucial element to make herd-health planning successful is the farmers' involvement in the consulting process $[6,7,11,12]$. Several surveys came to the conclusion that farmers have to be actively involved in identifying their problems, their individual aims and choosing the measures to take. Furthermore, farmers should summarise why they chose certain measures to implement changes and improvements of animal welfare on their farms $[6,9,11,12]$. This active involvement of the farmers was highlighted by the farmers in the present study as well. It is important that the farmers' perceptions of the current problems of their herds guide the process during a meeting, even if external persons like fellow farmers, advisers or veterinarians have different, probably even conflicting opinions [1]. In the present study, the percentage of measures which were chosen to be implemented by the farmers at the annual meetings in 2012 as well as in in 2016/2017 was lower compared to results of surveys where farmers implemented between $57 \%$ and partly $\geq 75 \%$ in Austria and Germany, and between less than one-third and up to more than two-thirds of the given measures in England and Wales (although that surveys stated the percentage of already implemented measures) $[3,8,15]$. Nevertheless, it should be taken into consideration that the compliance probably depends on the scale of implementing a certain measure. The measures vary, for example, regarding the amount of time required or costs. Liming the lying areas of the cows one more time per week would probably more likely be implemented by farmers than cleaning the cows' lying areas twice a day instead of once only. Tube feeding every newborn calf shortly after birth with colostrum implies also doing this at night, which probably will receive less acceptance among farmers. Analysing milk samples of each cow at drying-off and inserting teat sealants for every cow at drying off causes more direct costs, which probably leads to less acceptance as well.

To promote the eager implementation of measures, farmers have to be convinced of changing their management practice regarding different diseases. The best way of convincing farmers is to describe and consequently understand the implications of diseases for animal welfare on the one hand and for the economy on the other. Furthermore, as mentioned above, benchmarking can help to realise the suboptimal situation on a farm [15]. Action can only take place when a problem is detected. If a problem is perceived as less important or even not serious enough by the farmer, the information about it is not meaningful to him and therefore will not affect him [19,20]. Additionally, as motivation is crucial for the willingness to implement measures to improve herd health [8], a lack of motivation of the farmer may not lead to a successful implementation of the proposed measures [1]. However, apart from the assessment of the problem as being unimportant, the motivation of farmers depends on many internal as well as external factors. Internal factors are, for example, the management style (e.g. clean and accurate or dirty and quick) consisting of motivation, objectives and influences of specific factors relating to the production environment, for example, milk prices, attitude of the farmer to new techniques, investments or future goals, and personality (age, level of education, experience, ensured succession) [21]. Valeeva et al. [22], for example, found out that mainly factors which were internal to the farm performance and to the farmer like pleasure of healthy animals and ones' own reputation provided more motivation to improve mastitis management than external factors like, for example, esteem and performance of the dairy sector in general. Although the motivation for improving herd health differs among individuals [22], a lack of motivation seemed to be unlikely to explain the low rate of chosen measures of farmers in the present study because the participation in 
the consulting project was voluntary. Therefore, it can be assumed that farmers participating in this project wanted to improve animal health and welfare. Moreover, the results of Valeeva et al. [22] indicate that farmers are not solely motivated by money to improve their mastitis management. In contrast to the latter point, the analysis of the anonymous questionnaires in the present study showed that efficiency (business-related) is a very important factor for participating farmers when choosing a measure to implement on their farms. Probably this aspect is one reason for a relatively low number of measures in total chosen for implementation in the present study. In addition, practical constraints as well as limitations are seen as reasons for not implementing measures on farms in general [4]. Moreover, farmers are often influenced by legislation [4,23], common law and many institutions [23] which might also have played a role in the present study, especially in organic farming. This may affect the farmer's decision whether to choose and put proposed measures into practice or not.

Furthermore, the analysis of the anonymous questionnaires in the present study showed that a practicable implementation as well as the effectiveness were very important characteristics of those measures which were adopted on farms. This is totally consistent with the results of other surveys [19,24]. In contrast to Jansen et al. [19], in the present study (Table 2) and in a survey by Brinkmann [15], a short-term effect did not seem to be very important to farmers when choosing the measures they implemented on their farms. While the participants of another interventionproject more frequently implemented management measures, which resulted in changes in their daily work routines, and which also required small capital investments [3], Brinkmann [15] discovered the reverse: measures, which had to be integrated into the daily or weekly work-routine were less frequently implemented than technical solutions, which were implemented relatively fast. A possible reason for the former case is the necessary persistent discipline which is required during the daily routine [15]. Additionally, Brinkmann [15] stated that costs incurred by implementation of measures are not determinant whether to choose to implement a measure or not. Farmers in the present study, however, accepted management changes, especially in their daily work-routine, at least if the additional workload was low. The results of this study show that as long as im- plementing measures is successful and efficient (businessrelated), workable and less time consuming, farmers accept complex planning, structural or technical changes on their farm and a long period of time between implementing the measures and visible effects on herd health.

\section{Conclusion}

Based on the feedback of participating farmers, the concept of a consulting project including a special expert at each meeting seems to be very well accepted. In contrast to fears voiced by other authors, the participating farmers did not feel intimidated by the presence of an expert during the meetings. On the contrary, participating farmers positively highlighted the participation of different experts at each meeting, as the exchange of knowledge and experience with them were very important to most farmers. Moreover, they felt proven right after an expert had approved the measures they had proposed, making his contribution seem very important. In addition, the experts helped the farmers to understand the meaning and correlations of presented parameters through explanations during the annual consulting meetings. Furthermore, if farmers had the choice, they preferred to implement measures which had been proposed by their fellow farmers and later approved by the expert or those which had been proposed by the expert exclusively. To be chosen as measures, these measures should definitely be practical, effective and efficient (business-related) to implement and their implementation should only involve little additional daily workload.

Further analyses will be necessary to determine whether combining research and practice by bringing in experts on various topics to the existing group of farmers and the facilitator to combine research and practice was successful regarding the improvement of herd health parameters.

\section{Acknowledgments}

This study was financially supported by the Ministry of Food, Agriculture and Consumer Protection of Lower Saxony, Germany. The authors wish to thank the participating farmers for their participation, their involvement and for sharing their experiences with this kind of consulting project.

\section{References and Notes}

[1] Vaarst M. Animal Health and Welfare Planning in Organic Dairy Cattle Farms. The Open Veterinary Science Journal. 2011;5(1):19-25. doi:10.2174/1874318801105010019.

[2] Jones PJ, Sok J, Tranter RB, Blanco-Penedo I, Fall N, Fourichon $\mathrm{C}$, et al. Assessing, and Understanding, European Organic Dairy Farmers' Intentions to Improve Herd Health. Preventive Veterinary Medicine. 2016;133:84-96. doi:10.1016/j.prevetmed.2016.08.005.

[3] Tremetsberger L, Leeb C, Winckler C. Animal Health and Welfare Planning Improves Udder Health and Cleanliness but not Leg Health in Austrian Dairy Herds. Journal of Dairy Science. 2015;98(10):68016811. doi:10.3168/jds.2014-9084.

[4] Henriksen BIF, Anneberg I, Sørensen JT, Møller SH. Farmers' Perception of Stable Schools as a Tool to Improve Management for the Benefit of Mink Welfare. Livestock Science. 2015;181:7-16. doi:10.1016/j.livsci.2015.09.019.

[5] Vaarst M, Gratzer E, Walkenhorst M, Ivemeyer S, Brinkmann J, March $S$, et al. Farmer Groups for Animal Health and Welfare Planning in European Organic Dairy Hers; 2010. pp. 683-691.

[6] Vaarst M, Nissen TB, Østergaard S, Klaas IC, Bennedsgaard TW, Christensen J. Danish Stable Schools for Experiential Common 
Learning in Groups of Organic Dairy Farmers. Journal of Dairy Science. 2007;90(5):2543-2554. doi:10.3168/jds.2006-607.

[7] Ivemeyer S, Bell N, Brinkmann J, Cimer K, Gratzer E, Leeb C, et al. Farmers Taking Responsibility for Herd Health Development-Stable Schools in Research and Advisory Activities as a Tool for Dairy Health and Welfare Planning in Europe. 4th ISOFAR Scientific Conference at the Organic World Congress 2014 'Building Organic Bridges'. 2014;pp. 363-366. doi:10.1007/s13165-015-0101-y.

[8] Green MJ, Leach KA, Breen JE, Green LE, Bradley AJ. National Intervention Study of Mastitis Control in Dairy Herds in England and Wales. Veterinary Record. 2007;160(9):287-293. doi:10.1136/vr.160.9.287.

[9] Vaarst M, Roderick S, Smolders G, Leeb C, Walkenhorst M, Winckler C. The Dialogue with Farmers: Interview Results, Analysis and Reflections on Farmers, Dialogue in Relation to Animal Health and Welfare Planning: Deliverable 4.2 of the ANIPLAN Project. 2011;Accessed on 7 April 2019. Available from: https://pure.au.dk/ws/files/ 34777275/The_dialogue_with_farmers.pdf. Accessed on 7 April 2019.

[10] Vaarst M, Walkenhorst M, Smolders EAA. Communication in Animal Health and Welfare Planning. Planning for Better Animal Health and Welfare: Report from the 1st ANIPLAN Project Workshop. 2008;Accessed on 16 March 2019. Available from: http://orgprints.org/13408. Accessed on 16 March 2019.

[11] Bennedsgaard TW, Klaas IC, Vaarst M. Reducing Use of Antimicrobials - Experiences from an Intervention Study in Organic Dairy Herds in Denmark. Livestock Science. 2010;131(2-3):183-192. doi:10.1016/j.livsci.2010.03.018.

[12] Ivemeyer S, Smolders G, Brinkmann J, Gratzer E, Hansen B, Henriksen BIF, et al. Impact of Animal Health and Welfare Planning on Medicine Use, Herd Health and Production in European Organic Dairy Farms. Livestock Science. 2012;145(1-3):63-72. doi:10.1016/j.livsci.2011.12.023.

[13] Main DCJ, Leach KA, Barker ZE, Sedgwick AK, Maggs CM, Bell $\mathrm{NJ}$, et al. Evaluating an Intervention to Reduce Lameness in Dairy Cattle. Journal of Dairy Science. 2012;95(6):2946-2954. doi:10.3168/jds.2011-4678.

[14] March S, Brinkmann J, Winckler C. Improvement of Animal Health in Organic Dairy Farms through 'Stable Schools': Selected Results of a Pilot Study in Germany. Organic Agriculture. 2014;4(4):319-323. doi:10.1007/s13165-014-0071-5.
[15] Brinkmann J. Tiergesundheit in der ökologischen Milchviehhaltung Status quo sowie (Weiter-) Entwicklung, Anwendung und Beurteilung eines präventiven Konzeptes zur Herdengesundheitsplanung; 2010 Available from: https://ediss.uni-goettingen.de/bitstream/handle/ 11858/00-1735-0000-000D-EF42-9/march.pdf?sequence $=1$.

[16] Bell NJ, Main DCJ, Whay HR, Knowles TG, Bell MJ, Webster AJF. Herd Health Planning: Farmers' Perceptions in Relation to Lameness and Mastitis. Veterinary Record. 2006;159(21):699-705. doi:10.1136/vr.159.21.699.

[17] Bourdieu P. In Other Words: Essays Towards a Reflexive Sociology. Stanford University Press, Stanford, California; 1990.

[18] Vaarst M, Roderick S. Implementation of Farmer Groups for Animal Health and Welfare Planning Considering Different Contexts. ANIPLAN Project Workshop;Accessed 16 March 2019. Available from: http://orgprints.org/15920. Accessed 16 March 2019.

[19] Jansen J, Steuten CDM, Renes RJ, Aarts N, Lam TJGM. Debunking the Myth of the Hard-to-reach Farmer: Effective Communication on Udder Health. Journal of Dairy Science. 2010;93(3):1296-1306. doi:10.3168/jds.2009-2794.

[20] Moore DA, Payne M. An Evaluation of Dairy Producer Emergency Preparedness and Farm Security Education. Journal of Dairy Science. 2007;90(4):2052-2057. doi:10.3168/jds.2006-563.

[21] Barkema HW, Van der Ploeg JD, Schukken YH, Lam TJGM, Benedictus G, Brand A. Management Style and Its Association with Bulk Milk Somatic Cell Count and Incidence Rate of Clinical Mastitis. Journal of Dairy Science. 1999;82(8):1655-1663. doi:10.3168/jds.s00220302(99)75394-4.

[22] Valeeva NI, Lam TJGM, Hogeveen H. Motivation of Dairy Farmers to Improve Mastitis Management. Journal of Dairy Science. 2007;90(9):4466-4477. doi:10.3168/jds.2007-0095.

[23] Leeuwis C. Rethinking Agricultural Extension. In: Communication for Rural Innovation. vol. 03. Blackwell Science Ltd., Oxford, UK; 2004. pp. 1-1. doi:10.1002/9780470995235.part1.

[24] Rehman T, McKemey K, Yates CM, Cooke RJ, Garforth CJ, Tranter RB, et al. Identifying and Understanding Factors Influencing the Uptake of New Technologies on Dairy Farms in SW England Using the Theory of Reasoned Action. Agricultural Systems. 2007;94(2):281293. doi:10.1016/j.agsy.2006.09.006. 